\title{
Um novo olhar sobre a vida acadêmica: estudo de caso sobre as concepções de docentes ${ }^{1}$
}

\author{
Joana G. Aguiar² \\ ORCID: 0000-0002-4111-3058 \\ Paulo Rogério Miranda Correia ${ }^{2}$ \\ ORCID: 0000-0003-2419-7103
}

\section{Resumo}

As universidades têm investido tempo e dinheiro para melhoria da qualidade do ensino de graduação. Mesmo assim, os resultados obtidos ficam aquém das expectativas. Além disso, os docentes universitários estão inseridos em um ambiente profissional complexo em que o potencial de estresse é alto. Essas preocupações, de caráter global, levaram um docente britânico a propor o modelo da fragilidade pedagógica (MFP) como forma de integrar elementos-chave que descrevem as atividades docentes e os principais motivos que levam muitos docentes (incluindo os mais experientes) a adotar uma abordagem de ensino conservadora, tradicional, segura e, possivelmente, desatualizada. 0 objetivo deste artigo é apresentar uma breve revisão teórica sobre o MFP e explorar sua aplicação prática no cenário educacional brasileiro. Ao utilizar a metodologia de entrevistas baseadas na coconstrução de mapas conceituais, um estudo de caso foi conduzido com sete docentes universitários. As concepções e visões de ensino dos docentes foram analisadas e comparadas entre si considerando as dimensões do MFP. Os resultados mostraram que essas são individualizadas e sensíveis aos cursos e disciplinas que lecionam, às suas formações acadêmicas, ao tempo na carreira e aos valores do instituto, departamento ou escola a que pertencem. 0 MFP aliado ao mapeamento conceitual permitiu um diálogo aberto, franco e focado no indivíduo. As evidências sugerem uma potencialidade de aplicação do MFP para o desenvolvimento pedagógico docente no Brasil. Algumas contribuições, limitações e desafıos à disseminação do modelo também são apresentados.

\section{Palavras-chave}

Concepção dos docentes - Desenvolvimento docente - Ensino superior - Fragilidade pedagógica - Mapas conceituais.

1- Os autores agradecem aos docentes que participaram desta pesquisa e ao professor lan Kinchin, pelas discussões e contribuições. JGA agradece à CAPES pela bolsa de doutorado e doutorado sanduíche (\#88881.135605/2016-01).

2- Universidade de São Paulo, São Paulo, SP, Brasil. Contatos: joanaguilares@usp.br; prmc@usp.br 


\section{A new look at academic life: a case study of teachers' conceptions}

\section{Abstract}

Universities have invested time and money to improve the quality of undergraduate education. However, the results obtained fall short of expectations. Furthermore, higher education professors are in a complex work environment which is potentially stressful. These concerns, which are global, led a British professor to propose the pedagogic frailty model (PFM) as a way to integrate key elements that describe teaching activities and main reasons that lead many professors (including the most expert ones) to adopt a conservative, traditional, safe and possibly out-of-date teaching approach. The purpose of this paper is to present a brief theoretical review of PFM and explore its application in the Brazilian educational scenario. An interview-driven methodology for the co-construction of Concept maps was used to conduct a case study with seven university professors. Their conceptions and views of teaching were analyzed and compared to each other considering the PFM. The results show that professors' conceptions are individualized and sensitive to their course and discipline, background, career length and institutional values. The PFM combined with conceptual mapping allowed for an open, straightforward and personcentred dialogue. Evidence suggests that PFM can be potentially applied for teaching development in Brazil. Some contributions, limitations and challenges in disseminating the model are also presented.

\section{Keywords}

Conceptual maps - Higher education - Pedagogic frailty - Teachers' conceptions Teaching development.

\section{Introdução}

0 sistema de ensino superior está reinventando-se. Atualmente, ele funciona em uma sociedade baseada na explosão do conhecimento e no desenvolvimento das tecnologias da informação e comunicação (BERNHEIM; CHAUÍ, 2008). A crescente importância da ciência, tecnologia e inovação demanda novas formas de criar e disseminar o conhecimento. As instituições de ensino superior são desafiadas a propor soluções para formar profissionais que sejam capazes de não apenas aplicar tecnicamente o conhecimento específico, mas também de criar soluções inovadoras que respondam a problemas presentes e futuros em uma sociedade cada vez mais complexa (UNESCO, 2005). Nesse contexto, as universidades investem tempo e esforços para melhorar o ensino oferecido aos seus alunos.

A avaliação docente, entendida como a avaliação sistemática de desempenho didático-pedagógico dos docentes, é um ponto crítico para promoção da melhoria da 
qualidade do ensino de graduação ${ }^{3}$ (GOERGEN, 2001). Para que essa melhoria seja perceptível aos alunos e à comunidade acadêmica é necessário comprometimento institucional para promoção permanente de políticas de desenvolvimento profissional docente e de acompanhamento dessas melhorias (GONÇALVES, 2009). No ambiente universitário, essas políticas são difundidas como formação permanente, formação contínua ou continuada, formação em serviço, desenvolvimento de recursos humanos, aprendizagem por toda a vida, cursos de reciclagem ou capacitação. Dentre as várias definições de desenvolvimento docente existentes na literatura, destacamos aquela proposta por Heideman (1990, p. 4, tradução nossa):

0 desenvolvimento profissional dos docentes vai para além de uma etapa meramente informativa; implica adaptação à mudança com o fim de modificar as atividades de ensinoaprendizagem, alterar as atitudes dos docentes e melhorar os resultados escolares dos alunos. 0 desenvolvimento profissional de docentes preocupa-se com as necessidades individuais, profissionais e organizacionais.

Nas últimas décadas, pesquisas voltadas à pedagogia universitária vêm informando ações de desenvolvimento didático-pedagógico nas universidades brasileiras (ISAIA; BOLZAN, 2009; TORRES, 2014). Mesmo assim, os resultados obtidos ficam aquém das expectativas. De acordo com Barnett (2005), os desafios contemporâneos enfrentados pelas instituições de ensino superior apresentam grande complexidade e não podem ser adequadamente respondidos por ações isoladas. A visão fragmentada dos elementos que constituem a prática docente, tais como o planejamento do ensino, as concepções sobre o papel do currículo e as cobranças institucionais referentes à pesquisa, ensino e extensão, levam a uma perspectiva parcial do problema e à produção de respostas pouco adequadas para encaminhar soluções robustas.

Essas preocupações, de caráter global, levaram um docente britânico a propor um panorama teórico-prático denominado modelo da fragilidade pedagógica (KINCHIN et al., 2016; KINCHIN; WINSTONE, 2017). Tal modelo integra elementos relevantes para descrever as atividades docentes no ensino superior, iluminando os principais motivos que levam muitos docentes (incluindo os mais experientes) a enfrentarem situações estressantes no ambiente acadêmico. De modo geral, a fragilidade pedagógica (FP) pode ser observada quando colegas perdem a capacidade de se adaptar a mudanças repentinas, situações inéditas ou a um ambiente de ensino complexo em constante evolução (KINCHIN, 2015b). No âmbito do desenvolvimento docente, esse modelo surgiu com o intuito de ajudar no processo de integração dos esforços institucionais para que a melhoria da qualidade do ensino de graduação alcance maior repercussão (KINCHIN; CABOT, 2016).

0 objetivo deste artigo é apresentar o modelo da fragilidade pedagógica (MFP) e explorar sua aplicação prática no cenário educacional brasileiro, levantando as

\footnotetext{
3- Definir o conceito de qualidade do ensino de graduação não é tarefa fácil, pois muitas concepções e perspectivas sobre esse assunto são relatadas na literatura. Neste trabalho, adotamos o conceito de qualidade de ensino como transformação de concepções e práticas de ensinar e de aprender (BARNETT, 2005; DEMO, 1990; VIEIRA et al., 2009). Conforme salientam Almeida e Pimenta (2009), a qualidade como transformação pressupõe a adoção de uma pedagogia universitária emancipatória e crítica, capaz de gerar mudanças profundas nos docentes, discentes e na cultura acadêmica.
} 
concepções de alguns docentes universitários. Para isso, o texto foi organizado em quatro seções. A primeira apresenta uma breve revisão da literatura no que tange ao MFP e suas dimensões constitutivas. A segunda e a terceira seções apresentam os caminhos metodológicos da pesquisa e os resultados do estudo de caso no qual foram levantadas as concepções de docentes sobre as dimensões do MFP utilizando entrevistas mediadas por mapas conceituais. A última seção apresenta as considerações finais que delineiam contribuições, limitações e perspectivas do MFP para o desenvolvimento pedagógico de docentes do ensino superior.

\section{O modelo da fragilidade pedagógica e suas dimensões: uma breve revisão da literatura}

As constantes pesquisas e discussões acerca da formação docente nas universidades estrangeiras originaram, em algumas delas, pequenos grupos de profissionais que se preocupam exclusivamente com o desenvolvimento pedagógico dos seus docentes (EGGINS; MACDONALD, 2003). Esses profissionais cumprem um papel de formador docente do ensino superior, que parte do pressuposto de que, por exemplo, ser bom engenheiro não implica necessariamente ser bom docente de engenharia. Enquanto o primeiro depende do conhecimento do conteúdo disciplinar (content knowledge), o segundo implica a integração entre conhecimento especializado e conteúdo pedagógico do conhecimento (Pedagogic Content Knowledge - PCK), ou seja, saber ensinar os conteúdos disciplinares (FERNANDEZ, 2014).

0 docente britânico Ian Kinchin exerce a função de desenvolvedor acadêmico há quase duas décadas, tendo visto a criação e a evolução do panorama teórico de certificação de qualidade pedagógica de acadêmicos (em inglês, Teaching Excellence Framework TEF) como parte das políticas públicas para educação, amplamente aceito e difundido no Reino Unido. Com base em sua experiência, ele conduziu um estudo piloto em 2014, entrevistando docentes da Universidade de Surrey. Os resultados desse estudo (KINCHIN et al., 2016; KINCHIN; FRANCIS, 2017) indicaram a existência de diferentes estressores, que ao se acumularem, transformam eventos relativamente pequenos (mudanças no ambiente acadêmico) em situações insustentáveis e impossíveis de serem acomodadas dentro de um modelo tradicional de ensino. A unificação desses estressores levou Kinchin a propor o conceito de fragilidade pedagógica como aquele que "ajuda a colocar foco simultâneo em uma série de ideias-chave com o objetivo de aprimorar o ensino no contexto universitário" (KINCHIN et al. 2016, p. 1, tradução nossa).

\section{O conceito de fragilidade pedagógica}

Conforme apresentado em Kinchin (2015b), o conceito de fragilidade pedagógica (FP) foi concebido a partir de uma analogia com a literatura médica. Nessa, a fragilidade desenvolve-se como consequência do declínio de uma gama de fatores que, coletivamente, resulta no aumento da vulnerabilidade desencadeada por eventos relativamente pequenos (CLEGG; YOUNG, 2011). Por exemplo, a fragilidade clínica pode ser verificada quando 
um indivíduo não é mais capaz de lidar com situações da vida cotidiana por causa da diminuição das suas capacidades social, intelectual, emocional e física.

Vários indicadores de fragilidade foram identificados na literatura médica nacional e internacional (ROCKWOOD, 2005; VERAS et al., 2007) e incluem, por exemplo: a incapacidade de integrar respostas à mudança devido ao estresse; a perda da capacidade de adaptação devido à complexidade; o desgaste resultante de esforços repetidos para se adaptar às mudanças; a sensação de fadiga quando uma mudança é implementada sem consulta. Esses fatores são muito semelhantes às pressões sentidas e relatadas pelos docentes universitários. Na prática, a FP é observada quando os acadêmicos, frente às pressões cumulativas do ambiente profissional, têm reduzida a sua capacidade de alterar práticas de ensino em resposta a um ambiente em constante transformação (KINCHIN et al., 2016). Nesse contexto, a adoção de uma abordagem pedagógica segura e sustentável caracteriza-se como o único caminho possível (CLEGG, 2008; BAILEY, 2014).

Uma abordagem de ensino mais conservadora pode levar a uma visão tradicional do processo de ensino-aprendizagem, na qual a mera transmissão do conteúdo tem papel preponderante. 0 docente, ao adotar uma abordagem centrada naquilo que eu já sei e o que funciona para mim, seleciona a informação que considera essencial para transmitir sua visão de ensino e, seletivamente, ignora o restante dos conteúdos e valores. 0 impacto dessa abordagem pode ser visto na formação do aluno, estruturada como uma cadeia linear de eventos e atividades que reforçam a memorização em detrimento da aprendizagem profunda. Conforme salienta Kinchin e Hay (2007, p. 43, tradução nossa):

\begin{abstract}
Redes ricas e complexas são indicativas de conhecimento especializado, mas que raramente são explicitadas para os alunos no curso do ensino. Em vez disso, estruturas simples e lineares compreendem a maioria dos planos de aula ou sequências didáticas. [...]. Assim, a abordagem de ensino predominante nas universidades e a evidência de ensinamentos autênticos conduzidos por pesquisa continuam a ser escassos. É provável que isso reforce os resultados de uma aprendizagem superficial entre os estudantes universitários sendo um impeditivo para o surgimento da condição de especialista.
\end{abstract}

Para Talbot (2004), a adoção dessa linearidade não permite o diálogo como parte do desenvolvimento pedagógico desses docentes, retratando uma certeza "autoritária" da existência de uma única rota de ensino possível do começo ao fim. Por outro lado, as universidades, ao se esforçarem pela melhoria da qualidade do ensino, podem acabar "homogeneizando suas abordagens para um ensino de excelência, suas práticas pedagógicas e a experiência geral dos alunos" (STEVENSON; BURKE; WHELAN, 2014, p. 39, tradução nossa). Nesse contexto, não há espaço para mudanças, criatividade e inovação. Consequentemente, a evolução rumo às melhores práticas de ensino é cada vez mais negligenciada sendo a universidade um centro educacional com maior FP e menores chances de formar profissionais competentes para atuar com problemas complexos (KINCHIN; LYGO-BAKER; HAY, 2008). 


\section{As dimensões do modelo da fragilidade pedagógica}

Kinchin e seus colaboradores (2016) mostraram que o primeiro passo para lidar com a FP é identificar as relações entre os fatores que contribuem para essa condição (Figura 1). Para isso, ele organizou os estressores identificados nos relatos dos docentes em quatro dimensões: discurso regulativo, pedagogia \& disciplina, nexo pesquisa-ensino e lócus de controle. Cada dimensão será brevemente apresentada a seguir.

De acordo com a teoria sociológica para a educação de Bernstein (2000), existem dois discursos que informam a construção e disseminação do currículo ${ }^{4}$ : o discurso instrucional, relativo às discussões que envolvem a sequência e distribuição das disciplinas nos períodos letivos, os mecanismos de instrução e avaliação, a atribuição dos docentes nas disciplinas e suas cargas horárias e, o discurso regulativo (Figura 1), relativo às discussões que envolvem as abordagens pedagógicas, as teorias subjacentes ao ensino-aprendizagem, os valores e pressupostos a serem alcançados através do currículo (SANTOS, 2003).

É muito comum observarmos longas reuniões pedagógicas que discutem e rediscutem a posição, inserção ou exclusão de disciplinas na grade curricular, sem a devida discussão dos impactos dessas mudanças nos valores inerentes à identidade profissional dos egressos. Essa prevalência do discurso instrucional, sem os subsídios do discurso regulativo, aumenta a FP devido à ausência de uma visão compartilhada de ensino.

A dimensão, pedagogia \& disciplina (Figura 1), diz respeito às linguagens adotadas em sala de aula pelos docentes ao ensinar conteúdos disciplinares e avaliar a aprendizagem ocorrida. A autenticidade do ensino verifica-se quando os docentes ajudam os alunos a compreender o papel do conteúdo especializado no contexto da futura prática profissional, extrapolando a mera transmissão de informações (SHAFFER; RESNICK, 1999). Pode-se dizer que a FP aumenta quando um corpo docente não compartilha as mesmas linguagens em prol da aproximação entre os conteúdos disciplinares e a prática profissional dos egressos, tanto no ensino como na avaliação. Na prática, é muito comum observarmos docentes que lecionam para os mesmos alunos, no mesmo semestre e, às vezes, dividem a mesma disciplina, mas que nunca conversaram acerca de como suas abordagens e linguagens de ensino podem ser complementares ou redundantes.

0 nexo pesquisa-ensino (Figura 1) tem sido discutido com frequência e profundidade tanto na literatura internacional (ROBERTSON, 2007; LIGHT; CALKINS; 2015) como nacional (NOVA; SOARES, 2012; SOUSA, 2014). Alguns autores apontam que o ensino deve ser considerado isoladamente de outros aspectos da prática acadêmica (ÅKERLIND, 2011) enquanto outros exploraram possíveis benefícios de se conectar pesquisa e ensino (DEMO, 1998; HEALEY, 2005). Ainda que não haja um consenso na literatura, tensões não resolvidas entre pesquisa e ensino podem ser uma potencial fonte de estresse e mal-estar na vida acadêmica (MAGALHÃES, 2013).

4- Basil Bernstein e Michael Young fizeram parte do movimento Nova Sociologia da Educação, que desmistificou o papel do conhecimento e postulou que a sua construção envolve relações de poder. Bernstein (1971) define que o currículo conta como conhecimento válido, ou seja, conhecimento especializado em nível disciplinar, organizado socialmente e recontextualizado ou adaptado a diferentes grupos de aprendizes. Para Young (2014), o currículo representa o "conhecimento poderoso", ou seja, conhecimento que é capaz de prover os alunos de recursos para explicações e para pensar alternativas dentro do seu campo de estudo. 
Figura 1 - 0 modelo da fragilidade pedagógica e suas quatro dimensões constitutivas, organizadas para enfatizar a tendência ao controle individual e institucional

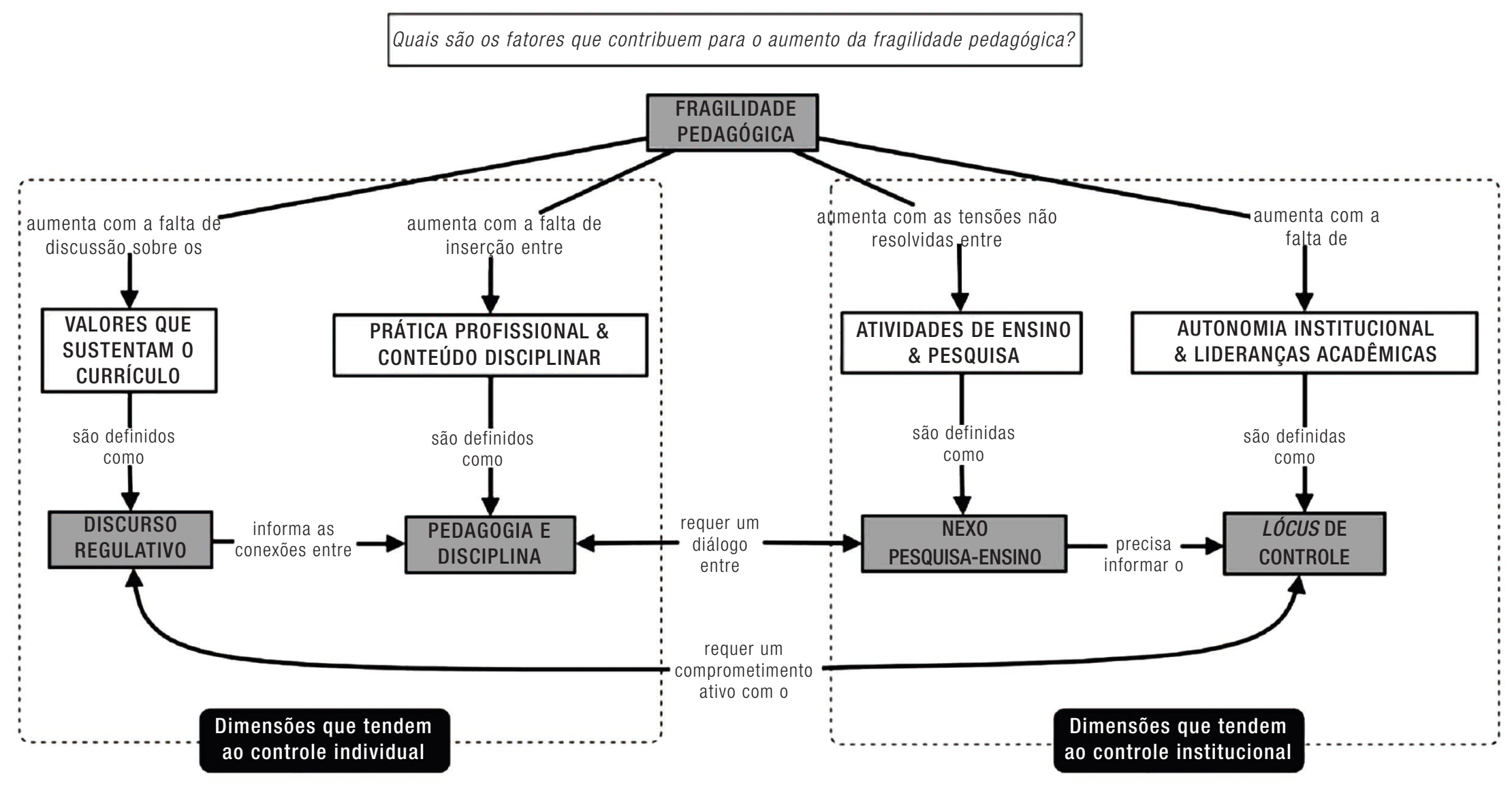


A indissociabilidade do tripé pesquisa, ensino e extensão (PUHL; DRESCH, 2016), instituída na Reforma Universitária (Lei 5540/68), requer habilidades de pesquisa e ensino como pré-requisitos dos acadêmicos, os quais devem ser fundidos ao invés de tomarem papéis separados. Nessa direção, Goergen (2001, p. 70) lembra-nos que "[...] ensino e pesquisa, embora representem noções e atividades de natureza distinta, parecem aproximar-se hoje na medida em que a aprendizagem envolve atitude de pesquisador". Entretanto, o que se percebe na prática é uma distribuição não balanceada de tempo e energia dedicados a tais atividades (ROBERTSON; BOND, 2001; HOSEIN, 2017). Uma maior valorização percebida à pesquisa ou ao ensino pode levar a um desequilíbrio que desencadeia desdobramentos assimétricos de recompensas, status, reconhecimento e motivação e, consequentemente, ao aumento da FP (YOUNG, 2006).

A quarta dimensão do modelo diz respeito a um elemento valorizado pelos docentes universitários: a autonomia profissional (CONTRERAS, 2002). As tensões entre os objetivos individuais e institucionais podem moldar nossa compreensão de autonomia, dependendo do nível de regulação imposto pela instituição e do espaço cedido para a negociação das práticas de ensino (KINCHIN, 2017). Nos últimos anos, algumas universidades deslocaram-se para uma administração mais centralizada, com modelos de avaliação da qualidade do ensino com uma visão "comercial” (GOERGEN, 2010), além de rigorosas abordagens de auditoria para medir a eficácia desse ensino prestado aos alunos (vistos aqui como consumidores). Já algumas universidades têm administração descentralizada, que permite maior participação da comunidade acadêmica nas tomadas de decisões que impactam o ensino e no processo de avaliação da qualidade (SOUSA SANTOS, 2010). A FP tende a aumentar com a falta do lócus de controle (Figura 1), ou seja, com a falta de autonomia institucional e de lideranças acadêmicas que avaliam e regulam as melhores práticas de ensino.

Kinchin (2017) argumenta que os acadêmicos tendem a ter certa dificuldade em relacionar as dimensões mais propensas ao controle individual com aquelas sob controle institucional (Figura 1). Por exemplo, os valores que subsidiam o currículo do curso deveriam auxiliar os docentes a estabelecer conexões significativas entre os conteúdos disciplinares e sua utilização no contexto da futura prática profissional dos egressos. Essas conexões poderiam dialogar com as pesquisas mais recentes da área, auxiliando docentes na seleção de temas e problemáticas atuais para serem discutidas com os alunos.

\section{Caminhos metodológicos da pesquisa: um estudo de caso com docentes universitários brasileiros}

A metodologia adotada nesta pesquisa é de caráter qualitativo, mais especificamente, um estudo de caso (CRESWELL; POTH, 2017). 0 estudo de caso não visa a produzir achados generalizáveis, mas fornecer uma riqueza de dados que seja valiosa para levantar questões de pesquisa e identificar padrões despercebidos. A partir da investigação de um fenômeno (as fontes de estresse no processo de ensino na academia), buscamos a compreensão da sua essência, a partir das visões, concepções, crenças e valores dos indivíduos em análise (os docentes).

Os participantes da pesquisa foram sete acadêmicos de uma universidade pública paulista identificados aqui pelas letras de A a G. Todos os docentes foram contratados sob um regime de dedicação exclusiva para realizar atividades de ensino, pesquisa, extensão e 
gestão. Coincidentemente, os docentes são das áreas de Ciências Naturais (Química, Física, Biologia) ou de Ensino de Ciências Naturais, tendo suas formações acadêmicas e linhas de pesquisa voltadas a essas mesmas áreas.

\section{Entrevistas mediadas por mapas conceituais e 0 procedimento de coleta dos dados}

0 conceito de FP entrou em cena como parte de um estudo exploratório mais amplo das estruturas de conhecimento de docentes, de diferentes áreas de conhecimento, sobre as práticas de ensino e aprendizagem na universidade. A representação dessas estruturas de conhecimento foi facilitada pelo uso dos mapas conceituais (KINCHIN, 2015a, 2016b).

Mapas conceituais são organizadores gráficos formados por uma rede de proposições que permitem a representação e visualização gráfica da estrutura de conhecimento de um sujeito sobre um determinado tema (NOVAK, 2010). As proposições são formadas por dois conceitos unidos por meio de um termo de ligação com verbo e uma seta que orienta a leitura da proposição. Normalmente, os conceitos são hierarquicamente organizados e toda a rede proposicional responde a uma pergunta focal específica (AGUIAR; CORREIA, 2013). Por exemplo, a Figura 1 apresenta um mapa que responde à pergunta focal "Quais são os fatores que contribuem para o aumento da FP?" e, "Discurso regulativo - informa às relações entre $\rightarrow$ Pedagogia \& disciplina” ilustra o que é uma proposição.

A visualização inicial do modelo e os estudos conduzidos até o momento foram, portanto, dependentes do uso dos mapas, sendo essencial que esses tenham a mais alta qualidade de estrutura e conteúdo (AGUIAR; CORREIA, 2017; CAÑAS; NOVAK; REISKA, 2015), a fim de representar com a maior precisão possível as concepções, visões e crenças dos docentes (CAÑAS; REISKA; MÖLLITS, 2017, CORREIA; AGUIAR, 2017, WILEY; FRANKLIN, 2017).

A coleta de dados envolveu entrevistas semiestruturadas mediadas por mapas conceituais. Entrevistas convencionais normalmente estabelecem-se por meio de perguntas e respostas em uma estrutura tipicamente linear (CRESWELL; POTH, 2017). A transcrição das entrevistas na íntegra, feitas a partir das gravações de áudio, gera grande quantidade de informação, demandando alto custo de tempo para o tratamento de dados. Já as entrevistas mediadas por mapas conceituais (KINCHIN; STREATFIELD; HAY, 2010) diferem substancialmente dessa dinâmica pois, permitem:

(1) a coconstrução do mapa conceitual à medida que a entrevista ocorre;

(2) a visualização do discurso do entrevistado por meio da atenção focada em conceitos-chave e proposições que têm alto caráter explicativo;

(3) maior flexibilidade ao entrevistador, que pode adequar sua abordagem e perguntas dependendo das respostas do entrevistado; e

(4) a correção, refinamento e validação do conteúdo exposto pelo entrevistado durante e logo após o fim da entrevista, dispensando a transcrição integral dos discursos.

Os sujeitos da pesquisa foram informados sobre os propósitos da pesquisa logo no início das entrevistas. Todos assinaram o Termo de Consentimento Livre 
e Esclarecido ${ }^{5}$. Cada docente foi convidado a contar um pouco sobre sua trajetória acadêmica, de modo que o pesquisador reunisse informações demográficas profissionais tais como, tempo na carreira, atribuições e atividades, local de trabalho, disciplinas ministradas na graduação. Em seguida, cada dimensão da FP (incluindo ela própria como dimensão) foram mapeadas sequencialmente. Cada entrevista foi iniciada oferecendo ao docente uma folha A3 em branco, conceitos escritos em notas autoadesivas e perguntas gerais declaradas verbalmente (Quadro 1).

Quadro 1 - Conceitos e perguntas fornecidas para iniciar a entrevista e a produção dos mapas conceituais de cada uma das dimensões da fragilidade pedagógica

\begin{tabular}{|c|c|c|}
\hline Dimensões & Conceitos iniciais dados & Perguntas declaradas verbalmente \\
\hline Discurso regulativo & $\begin{array}{l}\text { Avaliação; Conteúdo do curso; } \\
\text { Pressupostos; Sequência; Teorias; } \\
\text { Valores. }\end{array}$ & $\begin{array}{l}0 \text { que se fala de ensino dentro da universidade? } 0 \text { currículo do seu } \\
\text { curso está mais voltado para o desenvolvimento de valores ou para } \\
\text { a instrução? Qual o papel da avaliação no currículo? }\end{array}$ \\
\hline Pedagogia e disciplina & $\begin{array}{l}\text { Atividades; Autêntico; } \\
\text { Disciplinar; Estratégias; } \\
\text { Prática; Profissional. }\end{array}$ & $\begin{array}{l}\text { A linguagem da disciplina é a mesma linguagem do ensino da } \\
\text { disciplina? Considerando a disciplina que você leciona, o que se } \\
\text { ensina é de fato o que os alunos aplicarão no contexto profissional? } \\
\text { Em que medida o ensino e a avaliação são autênticos? }\end{array}$ \\
\hline Nexo pesquisa-ensino & $\begin{array}{l}\text { Ensino; Motivação; } \\
\text { Pesquisa; Recompensas; } \\
\text { Reconhecimento; Status. }\end{array}$ & $\begin{array}{l}\text { Considerando o contexto da universidade, da Unidade ou do seu } \\
\text { Departamento, onde está o foco: na pesquisa ou no ensino? Existe } \\
\text { ligação ou tensão entre essas atividades? Como elas se desdobram } \\
\text { em recompensas, reconhecimento, status e motivação? }\end{array}$ \\
\hline Lócus de controle & $\begin{array}{l}\text { Autonomia; Decisões; } \\
\text { Melhores práticas; Orientação; } \\
\text { Qualidade do ensino; Regulação. }\end{array}$ & $\begin{array}{l}\text { Onde são tomadas as decisões sobre o ensino ou que afetam o } \\
\text { ensino? Elas são centralizadas ou ocorrem fora da universidade? } \\
\text { Qual é o seu grau de autonomia nas tomadas de decisão? Como } \\
\text { se regulam as melhores práticas de ensino? Como se assegura a } \\
\text { qualidade do ensino? }\end{array}$ \\
\hline Fragilidade pedagógica & $\begin{array}{c}\text { Habilidade; Adaptar; Ambiente; } \\
\text { Complexidade; Estresse; Integrar; } \\
\text { Mudança; } \\
\text { Resiliência; Sustentável. }\end{array}$ & $\begin{array}{l}0 \text { que você costuma fazer quando o ambiente de ensino se torna } \\
\text { muito complexo ou quando você precisa fazer uma mudança em } \\
\text { função de algo externo? Existe estresse nesse processo? Qual o papel } \\
\text { da resiliência para você? Quando o ambiente se torna insustentável? }\end{array}$ \\
\hline
\end{tabular}

Fonte: os autores.

0 entrevistado (isto é, docente) prosseguiu sua narrativa, respondendo às perguntas e o entrevistador (isto é, pesquisador) manteve a discussão ativa solicitando, por meio de perguntas mais específicas, esclarecimentos sobre a conexão entre os conceitos e

5- Os procedimentos de coleta de dados seguiu os protocolos para condução de pesquisas com seres humanos conforme resolução da CNS 466/2012, tendo sido aprovado pelo Comitê de Ética e Pesquisa da instituição sob número CAAE: 40104314.7.0000.5390 - Número do Parecer: 950.171, Data da relatoria: 15/02/2015. 
os verbos presentes nos termos de ligação que explicitavam tais conexões. Durante o processo de coconstrução do mapa conceitual, o docente pôde incluir ou excluir conceitos e proposições à medida que a entrevista ocorria. Por fim, foi feita a leitura do mapa de modo a encontrar possíveis incorreções ou imprecisões, validando o seu conteúdo a partir das concepções, visões e crenças do docente. A apresentação inicial e a construção colaborativa dos cinco mapas conceituais levaram em média 30 minutos cada, resultando em uma entrevista de aproximadamente $3 \mathrm{~h}$ de duração por docente.

0 mapa conceitual construído durante a entrevista é tomado como uma representação aproximada dos modelos mentais do entrevistado sobre cada uma das dimensões da FP. As concepções sobre ensino, visualizadas nos conceitos e proposições dos mapas conceituais, constituem-se no principal resultado a ser analisado no âmbito dessa pesquisa ${ }^{6}$.

De posse dos 35 mapas conceituais coconstruídos durante as entrevistas, selecionamos cinco comparações (casos 1 a 5), considerando cada uma das dimensões constitutivas do modelo. A ideia foi explorar a validade do MFP aliado aos mapas conceituais como ponto de partida para reflexão da prática docente, bem como discutir os fatores que podem contribuir para a constituição das suas identidades profissionais (BEAUCHAMP; THOMAS, 2009; KREBER, 2010).

\section{Resultados e discussões: mapeando a concepção dos docentes universitários}

De modo geral, as entrevistas mediadas por mapas conceituais tornaram visível as concepções, muitas vezes implícitas, sobre temas que informam as atividades de ensino dos sete docentes sujeitos da pesquisa. Os casos de 1 a 5 , discutido a seguir, oferecem uma visão geral das concepções dos docentes, enquanto as informações sobre suas formações acadêmicas, o tempo na carreira docente e áreas de atuação na graduação permitiram uma melhor compreensão sobre os elementos que contribuem para o estabelecimento dessas concepções.

\section{Caso 1: Discursos regulativo vs. instrucional e a formação acadêmica}

0 primeiro caso compara os mapas sobre a dimensão discurso regulativo dos docentes A e B, da área de Ensino de Ciências (Figura 2). Ambos têm aproximadamente 12 anos na carreira acadêmica na mesma unidade de ensino e pesquisa e ministram aulas para o mesmo curso de Licenciatura em Ciências da Natureza. Apesar de vários conceitos aparecerem nos dois mapas, suas conexões com outros conceitos (as proposições) revelam diferenças marcantes.

\footnotetext{
6- Os mapas conceituais relatados nesta pesquisa não são fruto da interpretação dos autores/pesquisadores, mas sim da representação das concepções, visões e valores dos próprios entrevistados, revelados durante uma dinâmica de perguntas e respostas que ocorreu durante a entrevista semiestruturada. Tanto o procedimento de coleta como de análise dos dados seguiu o protocolo definido em Kinchin, Streatfield e Hay (2010).
} 
Figura +2 - Mapas conceituais de dois docentes A e B do Ensino de Ciências. Apesar de estarem atrelados ao mesmo curso e currículo, predomina o discurso regulativo por parte do docente A e o discurso instrucional por parte de $\mathrm{B}$
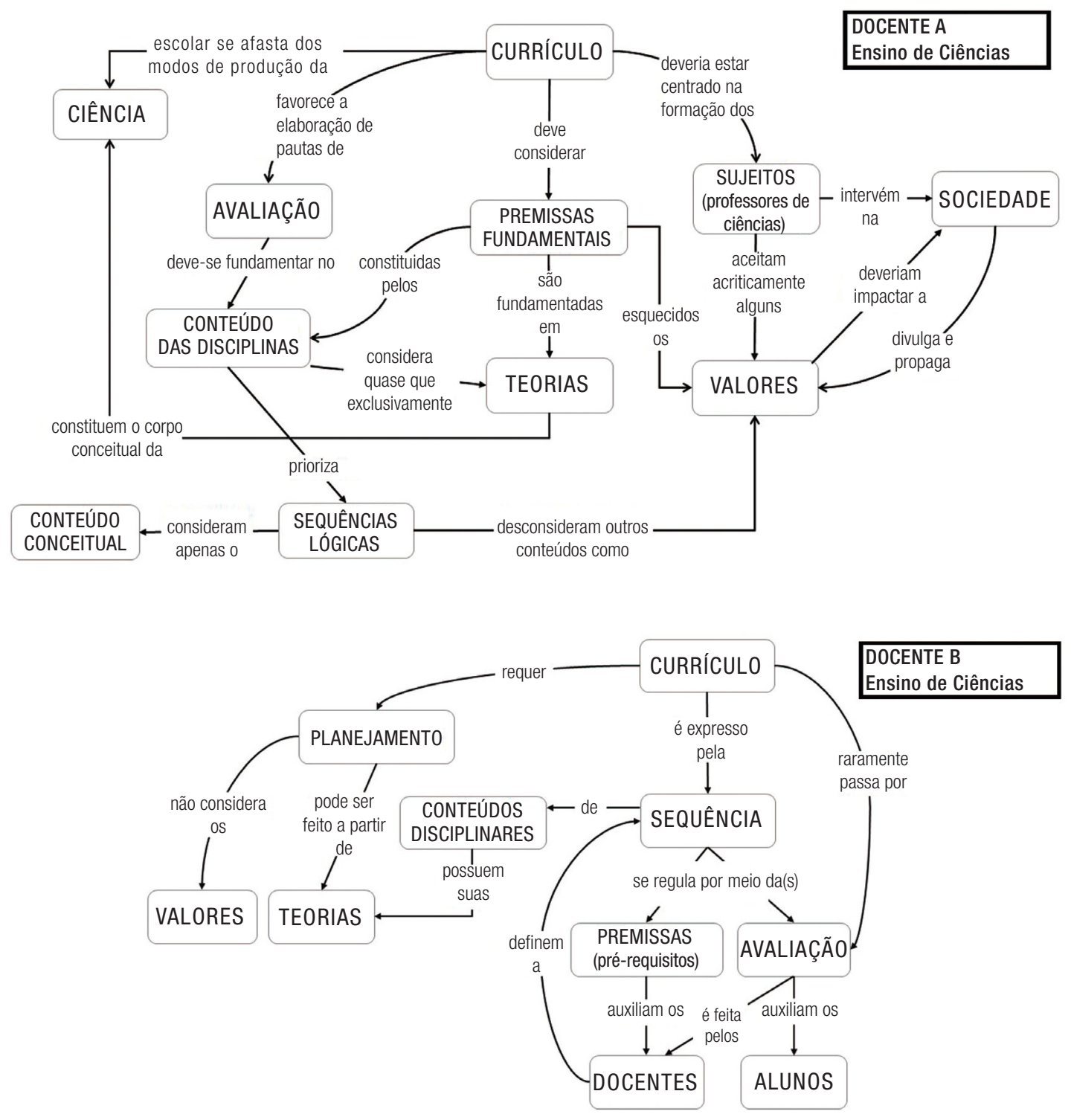

Fonte: os autores.

No primeiro mapa da Figura 2, é possível perceber uma predominância do discurso regulativo por parte do docente A uma vez que esse docente acredita que o currículo, 
pautado em premissas e teorias, deve estar centrado na formação dos futuros docentes de Ciências. Tanto o conteúdo conceitual e disciplinar como a sequência lógica do curso (discurso instrucional), são apresentados na base do mapa, tendo relevância menor em comparação aos demais conceitos. Isso pode ser observado neste trecho de sua fala:

0 currículo deve considerar premissas fundamentais de 'para quem' e 'para quê'. Ele é constituído pelas teorias, sendo estas o seu núcleo. 0 currículo atende ao indivíduo, considerando a formação do futuro professor de Ciências como um ser social que atuará na sociedade em seu entorno [...]. 0 grande problema é que, atualmente, o currículo deste curso privilegia mais os conteúdos disciplinares, com suas sequências lógicas, e menos a formação do sujeito. (Docente A).

Ao contrário dessa visão, o mapa da Figura 2 revela maior predominância do discurso instrucional por parte do docente B. Para ele, o currículo, expresso por uma sequência lógica de conteúdos disciplinares, requer planejamento. As premissas e teorias que embasam a construção desse currículo raramente passam por uma avaliação institucional. Por fim, ambos estão cientes da falta da inserção dos valores no currículo do curso ao qual estão atrelados. Essa visão fica clara quando o docente afirma que:

\begin{abstract}
Ainda que os valores existam, eles não são expressos, negociados ou compartilhados na definição do currículo [...]. Imagina que o currículo é uma sequência. Para que serve este currículo? Para que o aluno entre sem saber muita coisa da sua carreira e saia um profissional. 0 currículo é expresso muito mais por esta sequência de conteúdos disciplinares do que pelos valores, que são implícitos. (Docente B).
\end{abstract}

Uma possível explicação para as diferenças observadas são suas formações acadêmicas e linhas de pesquisa. Enquanto o docente A é formado em Biologia e Filosofia e se autointitula pesquisador da área de Educação (linhas de pesquisas: epistemologia e filosofia da ciência), o docente B é formado em Química com atribuições industriais e se autointitula pesquisador que está "mudando de área”, a partir de um interesse de pesquisa na área educacional (linhas de pesquisa: mapas conceituais, aprendizagem e instrução).

São raras as oportunidades, durante a vida acadêmica, para se discutir o impacto desse discurso sobre como o currículo será entregue aos alunos. Poder explicitar, compartilhar e discutir as diferentes visões e concepções sobre o currículo pode ser um ponto de partida para o desenvolvimento de um profissional mais reflexivo (SCHÖN, 2000) além da constituição de um currículo mais integrado (BERNSTEIN, 1971).

\title{
Caso 2: Pedagogia e disciplina e os cursos universitários
}

O segundo caso estabelece uma comparação entre os mapas dos docentes B e C (Figura 3), que ministram aulas de Química Geral para os cursos de Licenciatura em Ciências da Natureza e Bacharelado em Química, respectivamente. A inserção entre pedagogia e disciplina pode ser evidenciada, por exemplo, pelas relações conceituais no entorno do conceito profissional (em cinza na Figura 3). 0 primeiro mapa ressalta que, 
para o docente B, o conhecimento disciplinar subsidia a formação profissional. Porém, ainda que suas aulas abordem aspectos teóricos e práticos, não necessariamente elas precisam contemplar diretamente a formação para a prática profissional. Um exemplo observado na fala do docente, que justifica sua visão, coloca foco no papel da disciplina de Química Geral no curso de Licenciatura em Ciências:

\begin{abstract}
0 conteúdo disciplinar subsidia a formação profissional, mas as aulas não precisam contemplar diretamente esta formação. Por exemplo, ele está vendo na minha disciplina os conteúdos de termoquímica e cinética, mas ele ainda não está vendo como vai aplicar isso quando ele for professor. Quando ele for para uma disciplina de Ensino de Ciências da Terra e for estudar movimentos das placas tectônicas, ele vai resgatar os conhecimentos de termoquímica e cinética e, então, conseguirá ensinar Ciências tendo como base os conteúdos de Química. Por isso eu disse que subsidia, mas não contempla. (Docente B).
\end{abstract}

Em contrapartida, o segundo mapa evidencia que, para o docente C, o profissional precisará saber como resolver problemas reais com base na integração de diferentes fundamentos químicos e, por isso, suas aulas contemplam tanto os aspectos teóricos como as práticas de laboratório para solução desses problemas. Nesse caso, a disciplina de Química Geral tem papel fundamental na inserção dos conteúdos iniciais do curso, conforme o excerto extraído de sua fala:

Na minha aula os problemas são reais. Eu trago situações reais que acontecem nos laboratórios e nas indústrias para que os alunos resolvam. Para isso, eles precisam aplicar os fundamentos teóricos e, muitas vezes, realizar uma prática de laboratório para comprovar suas hipóteses [...] A disciplina introduz conceitos gerais e não específicos, então não há um conteúdo disciplinar rígido. (Docente C).

A similaridade nos discursos dos docentes refere-se às particularidades do ensino de Química, tais como a adoção de estratégias didáticas que envolvem fundamentos conceituais e teóricos da Química e aulas práticas de laboratório. Por outro lado, eles diferem quanto a inserção dessas linguagens para a formação do profissional, seja ele um Químico ou um futuro docente de Ciências.

0 enfoque curricular da disciplina Química Geral nos cursos aos quais esses docentes estão atrelados pode justificar as diferenças observadas entre seus discursos. No Bacharelado em Química, essa disciplina representa um primeiro contato que o aluno tem com o conteúdo específico do curso, porém, é a primeira disciplina de muitas que ainda virão ao longo dos próximos anos. Oferecer uma visão geral dos conteúdos que ainda serão abordados, valorizando o conhecimento prévio, a participação do aluno e atividades práticas que os motivam à prática investigativa, pode garantir a permanência no curso, evitando evasão precoce. Já no curso de Licenciatura, apenas duas disciplinas contemplam conteúdos de Química Geral, sendo elas, sequenciais, complementares e pouco redundantes. Possivelmente, o contato mais profundo com os fundamentos voltados às transformações químicas será abordado neste momento do curso, o que pôde ter contribuído para que o docente valorizasse os conteúdos disciplinares em detrimento 
Figura 3 - Mapas conceituais que revelam a inserção entre pedagogia \& disciplina dos docentes B e C. Ambos ministram aulas de Química, porém para cursos diferentes: Licenciatura em Ciências e Bacharelado em Química, respectivamente
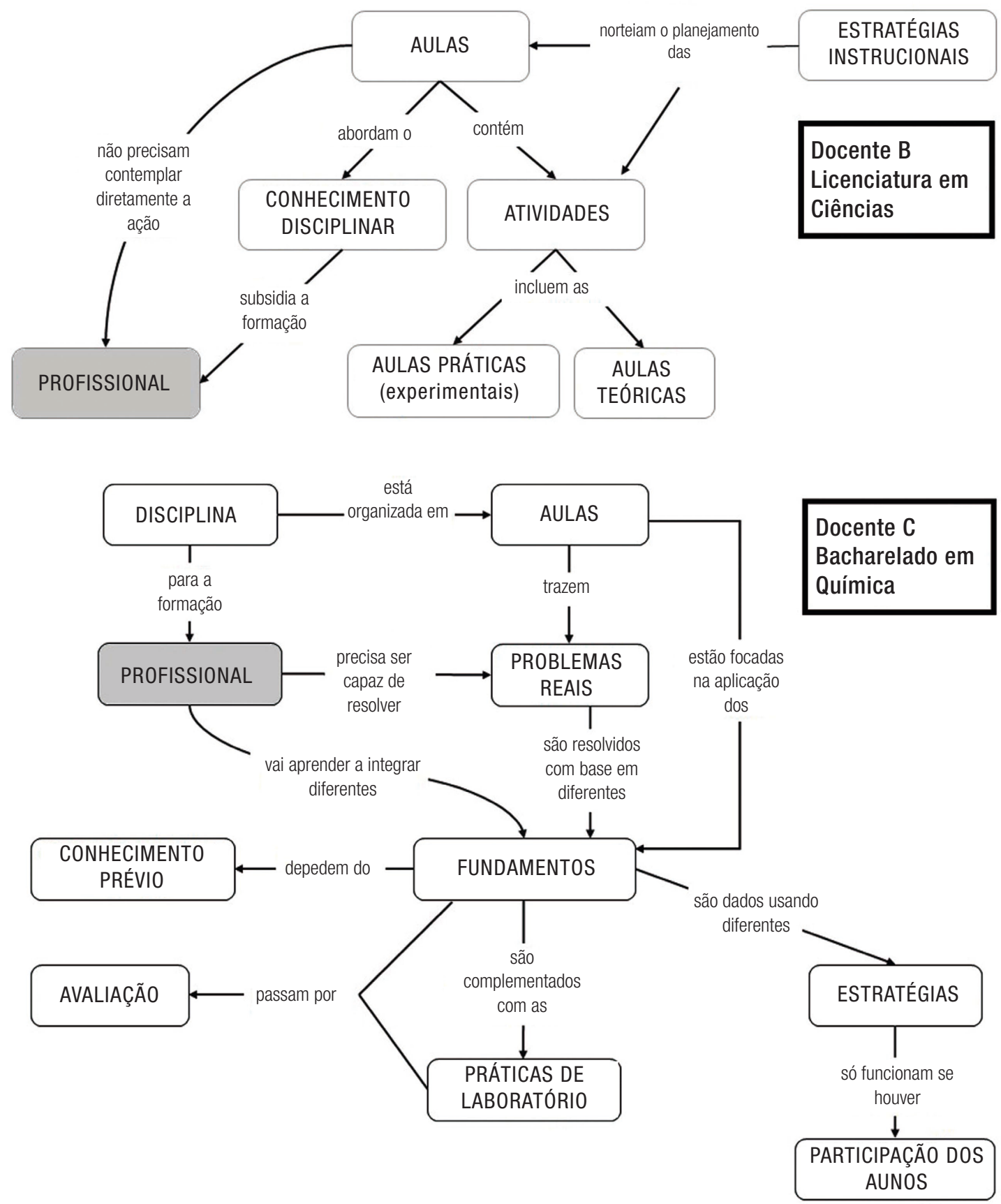

Fonte: os autores. 
dos valores e premissas. Já os saberes da prática profissional (saber ensinar Química), serão extensivamente trabalhados em outras disciplinas pedagógicas do curso, tais como metodologia, instrumentação e didática do ensino de Ciências.

\section{CASO 3: Nexo pesquisa-ensino e as expectativas da comunidade científica}

0 terceiro caso compara as conexões e tensões existentes entre as atividades de pesquisa e ensino na universidade retratadas nos mapas dos docentes B e D (Figura 4). 0 docente $\mathrm{B}$ tem 12 anos de profissão na área de Ensino de Ciências em uma unidade voltada às humanidades e ciências enquanto o docente D é Biólogo e tem 40 anos de profissão junto ao departamento de Bioquímica.

Em linhas gerais, eles compartilham a visão de que a universidade na qual estão inseridos valoriza mais as atividades de pesquisa do que ensino, levando à obtenção de um maior reconhecimento, status e recompensas por parte da instituição, da academia, dos alunos e dos pares quando o docente é um bom pesquisador. Apesar disso, a motivação e a satisfação pessoal estão presentes nas atividades relacionadas ao ensino. Isso pode ser verificado na fala do docente $B$ :

As atividades de ensino e pesquisa são assimétricas na universidade, devido à missão da própria instituição. Ela se declara como uma universidade de pesquisa; ela quer ser protagonista nos papers publicados no Brasil; ela se posiciona assim. Então, quem vem para esta universidade, sabe que vai ter a oportunidade de fazer pesquisa [...] Se eu faço pesquisa bem e eu sou um bom pesquisador, isso leva a uma maior recompensa, que pode ser tangibilizada, por exemplo, em um paper ou em um convite para uma parceria de pesquisa. Porém, eu me sinto tão motivado para fazer pesquisa como para o ensino...isso é totalmente pessoal e interno. (Docente B).

Aparentemente, o docente B apresenta uma visão simplificada e generalizada do nexo pesquisa-ensino quando comparado ao docente D. Provavelmente, isso ocorre, pois, o docente D tem maior tempo de carreira, apresentando uma visão mais detalhada tanto das expectativas da comunidade acadêmica (o uso de métricas de pesquisa para aprovar um candidato a docente no concurso da universidade), como das recompensas concretas oferecidas pela instituição (ascensão na carreira e aumento de salário).

Além disso, o docente D explicita com maior detalhamento os mecanismos de conexão entre ensino e pesquisa. Para ele, o conhecimento gerado na pesquisa expõe o docente a uma situação em que é preciso se movimentar para acomodar as novas informações e, então, ser capaz de oferecer estas aos seus alunos, tornando o ensino cada vez melhor. No excerto do seu discurso a seguir, fica clara a sua visão sobre a importância da pesquisa no ensino:

Quando o professor é também um pesquisador, isso o obriga a estar sempre atualizado. Estar exposto a este conhecimento gerado na pesquisa faz com que ele melhore o ensino, pois ele levará esse conhecimento para a sala de aula, para ser discutido com os alunos [...]. A universidade me cobra por mais resultados de pesquisa e eu, por me sentir mais motivado com o ensino, acabei conciliando as duas coisas fazendo pesquisa em ensino de bioquímica. (Docente D). 
Figura 4 - Mapas conceituais que revelam conexões e tensões entre as atividades de pesquisa e ensino segundo a visão dos docentes B e D. A visão dos dois docentes é muito similar, sendo que B apresenta uma visão mais simplista e generalista quando comparada a $D$

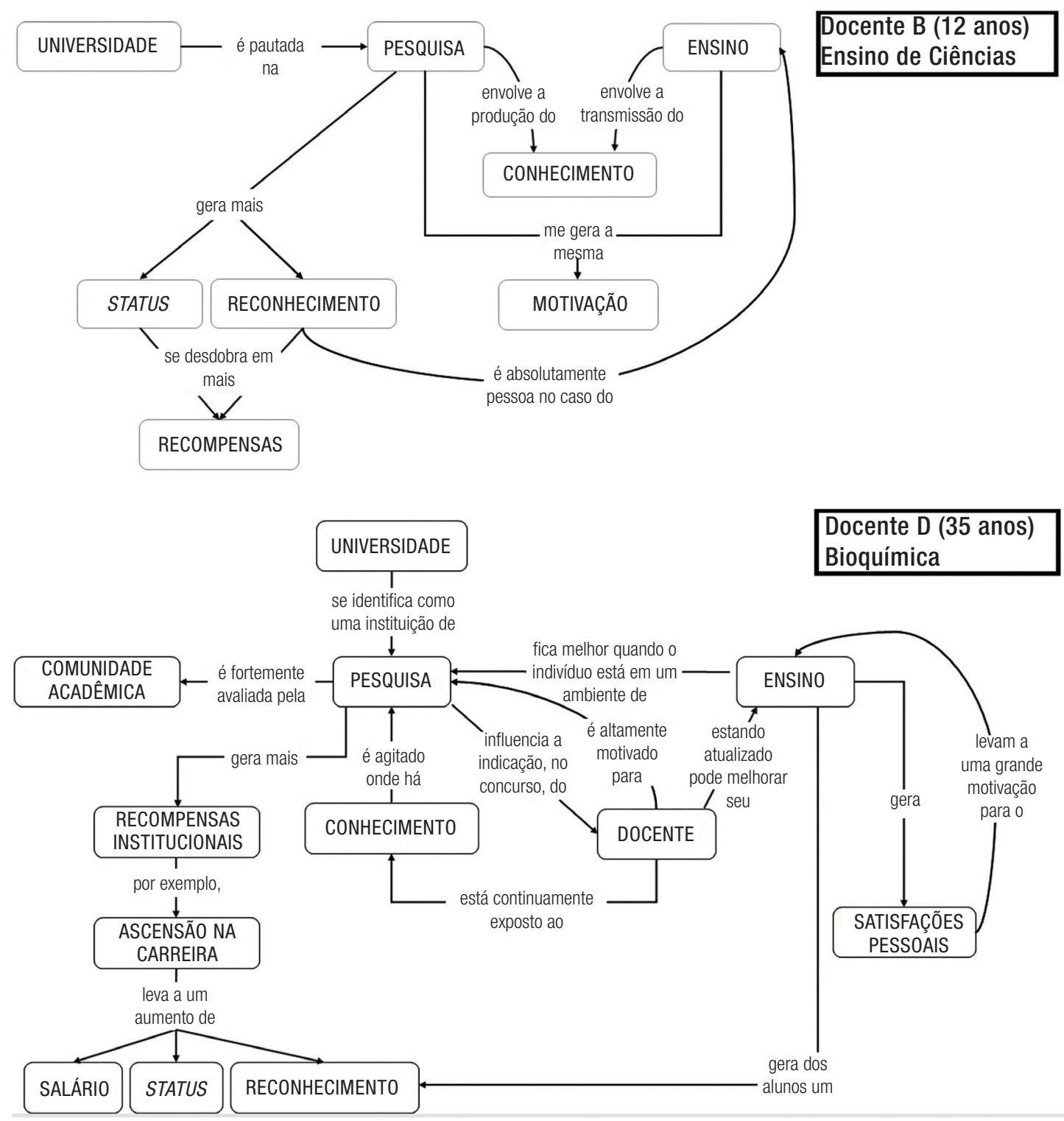

Fonte: os autores. 
Já para o docente $\mathrm{B}$ essa conexão é mais simplista - a pesquisa gera um novo conhecimento, o qual é, de alguma forma, transmitido ${ }^{7}$ aos alunos por meio das práticas de ensino. Apesar dos dois acadêmicos diferirem em suas formações acadêmicas, tempo na carreira e filiação, ambos apresentam uma visão compartilhada quanto ao nexo pesquisaensino. As expectativas da comunidade científica, que corroboram implicitamente com as expectativas da universidade, exercem forte influência em como os docentes perceberão as recompensas relativas às atividades de ensino e a pesquisa. Explicitar e compartilhar essas percepções podem auxiliar no alinhamento e/ou adaptação aos valores institucionais em vigor.

\section{CASO 4: Lócus de controle e os valores institucionais}

O quarto caso compara os mapas que refletem a percepção dos acadêmicos D e E a respeito das tomadas de decisões que impactam o ensino e da autonomia institucional e individual nas práticas acadêmicas (Figura 5). Ambos os docentes têm pelo menos 35 de carreira acadêmica na mesma universidade, porém, nas áreas de Educação (docente E) e Bioquímica (docente D).

0 docente $\mathrm{E}$ descreve um mecanismo generalista de regulação e avaliação detalhando o processo em nível institucional (PRG e UES), nacional (DCNs e CNE/MEC) ${ }^{8}$. As articulações entre esses níveis são complexas e podem ser explicitadas com mais detalhes na fala do docente:

A pró-reitoria de graduação precisa se subordinar às diretrizes de ensino, que vem pré-estabelecidas pelo conselho nacional de educação. Essas diretrizes são muito fechadas e homogeneizadas. Por exemplo, não é possível mudar a quantidade de horas de estágio que um aluno precisa fazer. Mas, pelo menos, os professores podem escolher os conteúdos que vão lecionar, dando uma certa autonomia individual. (Docente E).

Para ele, as unidades de ensino superior apoiam a autonomia docente e provêm mecanismos de avaliação em busca das melhores práticas de ensino. A presença de conselhos, comissões e congregações, formadas pelos próprios docentes da unidade e apoiadas por diretrizes e normas, representam sua percepção para um lócus de controle descentralizado e autônomo. Um padrão similar é observado no mapa do docente $\mathrm{D}$, ainda que este tenha descrito mecanismos de regulação e avaliação em nível departamental. No caso da Bioquímica, as decisões que impactam o ensino são divididas entre seus docentes, por meio de uma comissão, e a unidade de origem, que apresenta a demanda por disciplinas específicas. Essa dinâmica, muito particular do departamento de Bioquímica, fica clara na fala do docente:

A unidade de origem faz a solicitação por uma disciplina de 'xis' créditos aqui no departamento e, nós, definimos o professor que será responsável por essa disciplina considerando o curso e os

7- 0 docente B deixa claro em seu discurso que ele tem consciência de que o ensino não é apenas transmissão de conhecimento, mas sim um processo complexo de atribuição de significado e mudança na estrutura conceitual dos alunos. Porém, ele também afirma que, em certa medida, o docente tem a responsabilidade de escolher os conteúdos mais relevantes e transmiti-los aos alunos durante as práticas de ensino.

8- Acrônimos do texto e do mapa da Figura 5 - PRG: Pró-Reitoria de Graduação; UES: Unidade de Ensino Superior; CNE/MEC: Conselho Nacional de Educação do Ministério da Educação e Cultura; DCNs: Diretrizes Curriculares Nacionais. 
Figura 5 - Mapas conceituais dos docentes E e D que revelam concepções similares ao lócus de controle. Ambos os docentes têm 35 anos na carreira acadêmica, porém, em áreas distintas: Educação e Bioquímica

Docente E (35 anos)

\section{Educação}

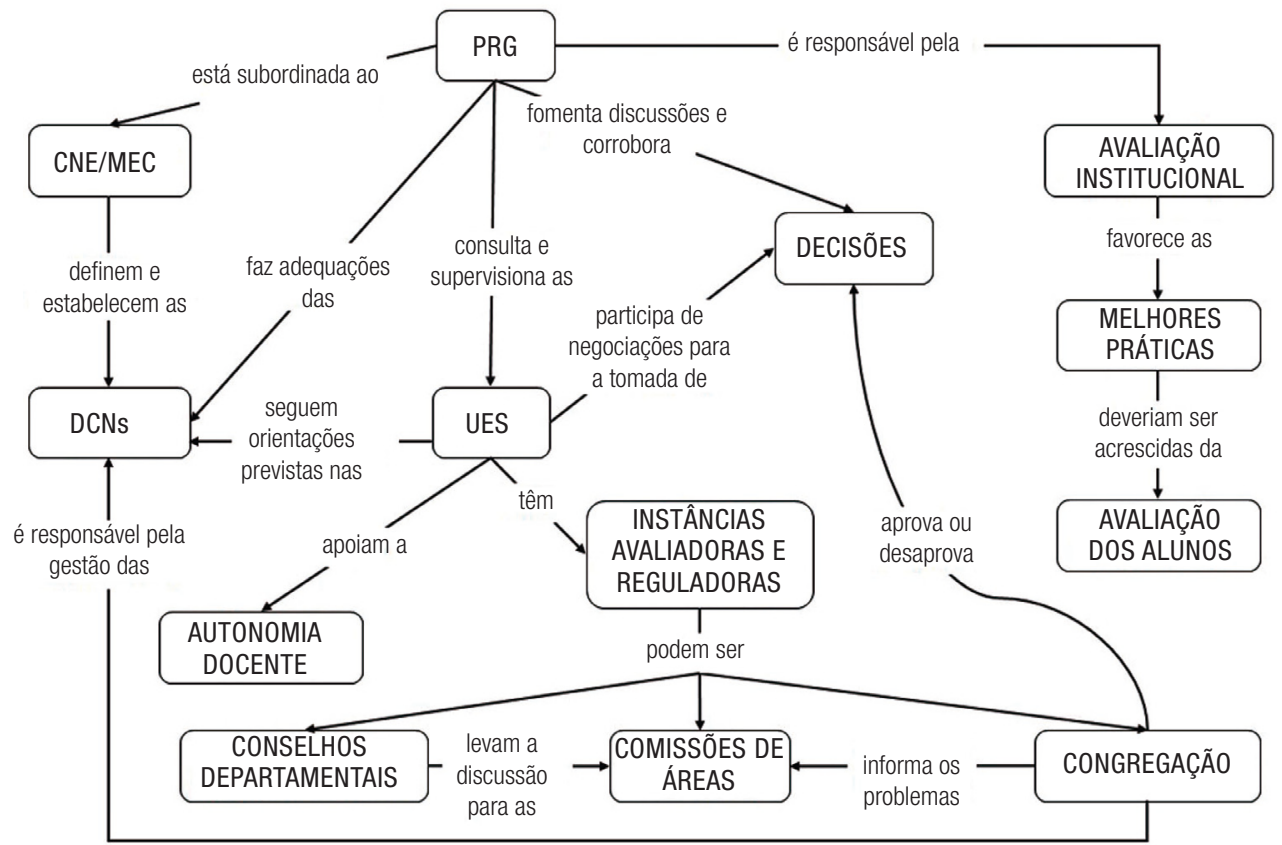

Docente D (35 anos)

Bioquímica

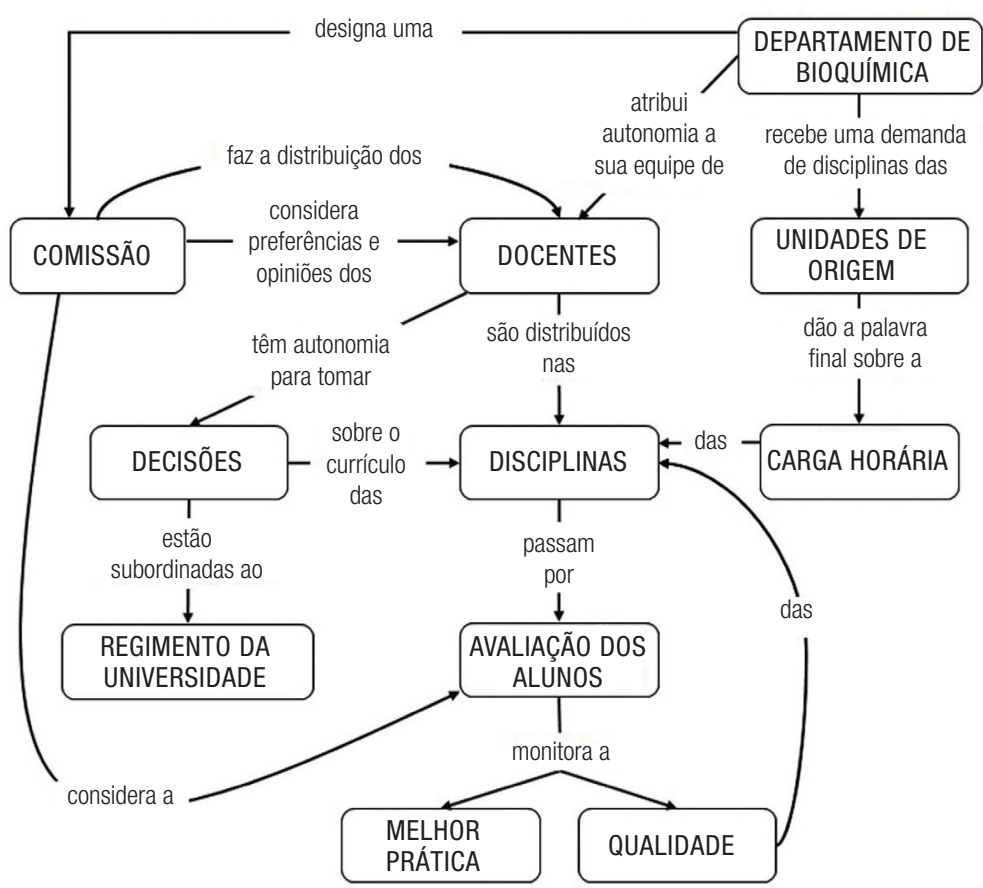

Fonte: os autores. 
objetivos. Por exemplo, se for Bioquímica para Medicina é um perfil e se for Bioquímica para Química é outro. (Docente D).

Um ponto de contraste no discurso dos docentes D e E refere-se ao papel dos alunos na busca pelas melhores práticas de ensino. 0 docente da Educação relata que:

Em meu departamento, os alunos não são incluídos nas dinâmicas de avaliação dos docentes. Não há uma avaliação sistemática em que se pergunta diretamente aos alunos o que eles acharam de cada professor. Quem toma as decisões são as comissões de área [...] ainda que eu ache que os alunos deveriam ser acrescidos dessa avaliação, isso não é feito. (Docente E).

Já o docente da Bioquímica afirma que, em seu departamento, a comissão considera a opinião dos alunos no momento de alocar docentes em suas respectivas disciplinas. Essa diferença revela que, mesmo sob um regimento geral da universidade, as unidades de ensino têm autonomia suficiente para implementar mecanismos de regulação da qualidade localmente, considerando para isso uma avaliação sistemática que passa por ouvir seus docente e alunos (DURHAM, [1989].).

Vale ressaltar que, para ambos os docentes, a presença de autonomia individual para as práticas de ensino (escolha dos conteúdos, avaliações e estratégias de ensino nas disciplinas) minimiza a sensação de falta de controle nas tomadas de decisão que mais impactam a qualidade do ensino (a falta de autonomia institucional).

\section{CASO 5: Estresse, resiliência acadêmica e o tempo na carreira}

0 último caso a ser ilustrado compara os mapas produzidos durante a entrevista com quatro docentes C, D, F e G (Figura 6) do Instituto de Química, a respeito da própria FP. Os docentes $\mathrm{C}$ e $\mathrm{D}$ têm mais de 25 anos de carreira acadêmica, enquanto os docentes $\mathrm{F}$ e $\mathrm{G}$ têm menos de 12 anos. Nitidamente, os mapas apresentam diferenças entre si, tanto em forma como conteúdo. Por exemplo, o conceito ambiente (em cinza na Figura 6) está presente em todos os mapas, mas com diferentes significados e níveis hierárquicos - desde o mais geral como o todo e o sistema educacional, até os mais específicos, como o Instituto de Química e a sala de aula.

Os docentes mais jovens na carreira (F e G) apresentaram uma visão mais negativa sobre a necessidade de adaptação e integração em um ambiente de alta complexidade. 0 docente $\mathrm{F}$ entende a resiliência como algo que impede o processo de mudanças, evidenciando uma concepção que se assemelha ao de resistência em vez de capacidade de lidar com a complexidade (HOWARD; JOHNSON, 2004). É possível observar em sua fala um sentimento de impotência, uma vez que para esse docente:

0 sistema educacional, de posse da autonomia e poder, poderia facilitar os processos complexos da prática docente, mas não o faz, dificultando a vida do professor. (Docente F).

0 docente $\mathrm{G}$ atribuiu às pessoas a sua volta (colegas) a fonte de complexidade e estresse do seu dia a dia, o que o leva, geralmente, ao estado de isolamento. Além 
disso, não há percepção de escolha quando as mudanças são impostas pelo Departamento, sendo a adaptação a única forma de sobrevivência nesse ambiente em constante evolução. Conforme relatado durante a entrevista, para esse docente:

As pessoas simplesmente não sabem conversar para chegar a um acordo. Normalmente, cada um está buscando para si o que é melhor. Quando as mudanças são impostas, as pessoas oferecem todo tipo de resistência. Para não discutir, eu acabo não me envolvendo em questões pedagógicas; acabo me isolando na minha sala e dando as minhas aulas. (Docente G).

Já os docentes com maior tempo na carreira acadêmica (C e D) apresentaram uma visão mais positiva no que tange à complexidade inerente ao processo e ambiente de ensino. 0 docente $\mathrm{C}$ também atribuiu aos seres humanos a imprevisibilidade e a complexidade do ambiente. Porém, em sua visão:

As mudanças podem ou não acontecer e isso vai depender de estímulos externos. Estes estímulos prepararam o professor para lidar com situações próprias do ambiente de ensino. Por exemplo, se eu preciso dar uma nova disciplina que nunca foi dada, isso é um estímulo externo que faz com que eu me adapte e me prepare para o que vai vir. Mas, da próxima vez que isso acontecer, eu já estarei mais preparado e terei aprendido a lidar com este tipo de imprevisibilidade. (Docente C).

O docente $\mathrm{D}$ revela encadeamento quase linear onde uma situação leva ou depende de outra para acontecer. Para ele, o equilíbrio desejado entre as partes do sistema (docente e alunos) não é estático, mas dinâmico. A complexidade, imposta pela sala de aula, é vista como algo natural. Esse docente não atribuiu às pessoas a presença de complexidade, mas sim da necessidade de as mudanças requererem reconciliação - na maioria das vezes não paritárias. Em suas palavras:

0 docente é a autoridade em sala de aula e o responsável por manter o equilíbrio entre as partes que compõe o sistema, evitando situações de estresse em face da complexidade. 0 sucesso deste processo dinâmico e natural depende da experiência do docente, adquirida ao longo da sua trajetória acadêmica. (Docente D).

No discurso de ambos os docentes $\mathrm{C}$ e $\mathrm{D}$, é possível observar um descritor semelhante ao de como as pessoas adquirem resiliência na vida, com o passar dos anos, por meio da interação com outros e de experiências providas pelo externo/ambiente (GROTBERG, 2005; TAVARES, 2001).

É importante ressaltar que, independentemente do tempo de carreira ou mesmo de uma visão mais positiva ou negativa sobre a complexidade de um ensino em evolução, a percepção e o conceito de estresse pode ou não estar presente em suas narrativas. Para dois dos docentes (G e D), o estresse se fez presente em seus discursos ainda que em contextos diferentes - das pessoas que compõem o sistema ou das próprias mudanças impostas no decorrer do processo de ensino e aprendizagem, respectivamente. 
Figura 6 - Mapas conceituais de docentes vinculados ao Instituto de Química, com diferentes tempos de carreira: mais antigos (C e D) e mais jovens (F e G). Seus discursos revelam significados diversos para o conceito "ambiente", o papel da resiliência e do estresse

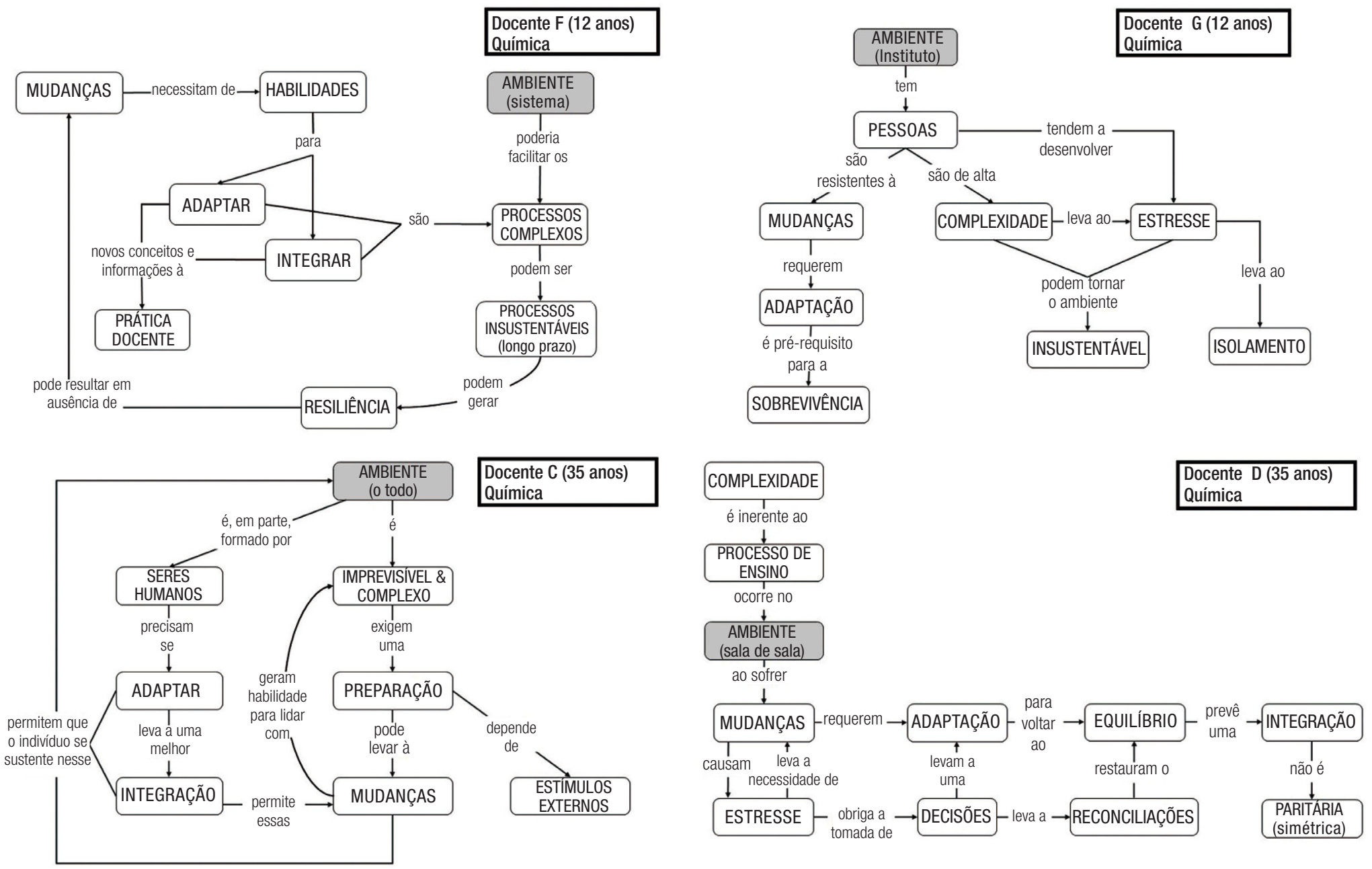




\section{Considerações finais: algumas contribuições, limitações e perspectivas}

Os acadêmicos que ensinam na universidade estão inseridos em um ambiente profissional complexo, com elevado potencial de estresse. O MFP foi desenvolvido para visualizar os fatores que contribuem para as atividades acadêmicas, a fim de proporcionar maior sensação de coerência sobre a nossa contribuição como docentes e para ajudar a gerenciar esse estresse.

Quando as dimensões do modelo estão em tensão umas com as outras, observa-se um ambiente marcado pela FP, no qual são preservadas as práticas de ensino tradicionais e conservadoras, possivelmente desatualizadas. Tornar visível, compartilhar, discutir e resolver tais tensões à medida que a vida acadêmica ocorre é um desafıo à formação docente e às instituições de ensino superior que desejam melhorar o ensino oferecido aos seus alunos. A busca por relações significativas entre as dimensões do modelo, a partir do estabelecimento de um diálogo aberto e franco dentro da academia, parece ser um ponto de partida para o desenvolvimento pedagógico sistemático dos docentes universitários.

0 estudo de caso, reportado neste artigo, mostrou (1) como entrevistas mediadas por mapas conceituais auxiliam a sistematizar, organizar e visualizar o discurso dos docentes, mantendo um foco atento aos elementos-chave que compõem cada dimensão do modelo e (2) como estabelecer, na prática, um ponto de partida para um diálogo produtivo com os docentes sobre suas trajetórias acadêmicas, opções didáticas, visões de ensino e pesquisa, concepções de currículo. De modo geral, os resultados mostraram que as visões, concepções e valores dos acadêmicos são individualizadas e sensiveis aos cursos e disciplinas que lecionam, ao tempo na carreira e aos valores do departamento, da unidade ou da instituição aos quais estão vinculados.

Além disso, o fato de os sujeitos da pesquisa serem todos da área de Ciências Naturais e/ou Ensino de Ciências também merece destaque. Tradicionalmente, as disciplinas acadêmicas classificada como "duras" (Química, Física, Matemática) apresentam pouca tradição em discutir questões pedagógicas que embasam seu ensino, voltando-se à aquisição de conhecimento atinente apenas aos conteúdos disciplinares. Mesmo os cursos de Licenciatura nessas áreas privilegiam o conteúdo especializado em detrimento à formação pedagógica, não oferecendo, portanto, subsídios práticos aos futuros docentes de Ciências. A criação dos cursos de pós-graduação em Ensino de Ciências vem contribuindo para a formação continuada desses docentes, além de permitir a inserção de uma nova geração de professores-pesquisadores nas universidades voltada para essa área, essencialmente interdisciplinar. Algumas comparações feitas neste artigo iluminaram a diferença entre as concepções de docentes dessas áreas, evidenciando a formação de uma identidade profissional socialmente constituída pelos seus membros.

Uma das principais limitações do modelo é o fato do conceito de fragilidade apresentar uma conotação negativa, muitas vezes sendo mal compreendido como "fraqueza" ou "limitação". Ao contrário da fragilidade médica, aquela pedagógica não

9- Biglan (1973) e depois Stoecker (1993) classificam as áreas de conhecimento acadêmicas (também chamadas de disciplinas) em três grandes grupos: duras ou moles, puras ou aplicadas e vivas ou não vivas. Por exemplo, Química é uma disciplina dura, pura, não viva, enquanto a Educação é uma área mole, aplicada, viva. 
deve ser considerada como uma capacidade individual do docente per se, mas sim, como resultado da qualidade e do grau de interação com os elementos-chave do ambiente profissional. Além disso, uma caracterização ou julgamento pessoal e individual é inútil quando se deseja obter a abertura necessária para o desenvolvimento docente. Para minimizar esta limitação, sugerimos uma releitura do MFP considerando um possível análogo positivo: a resiliência acadêmica. 0 mapa conceitual da Figura 7 mostra a nossa proposta de reformulação do modelo, dando ênfase na resiliência acadêmica.

Outro desafio à disseminação do modelo em larga escala é o tempo necessário para a condução das entrevistas. Além disso, há a necessidade de um pesquisador que compreenda não só o modelo, mas também a técnica de mapeamento conceitual aliada à metodologia de entrevistas. Estudos futuros devem direcionar pesquisas (1) em busca de formas mais ágeis de coleta de dados que possam substituir o processo de entrevista ou, pelo menos, reduzir o tempo necessário para sua condução; (2) para o desenvolvimento de atividades mediadoras de elaboração e edição de mapas conceituais, explorando as diferentes dimensões do modelo; (3) teóricas e práticas de revisão ou expansão do modelo considerando diferentes contextos, perfis docentes e áreas de conhecimento.

Figura 7 - Releitura dos autores sobre 0 modelo da fragilidade pedagógica da Figura 1, dando ênfase à resiliência acadêmica

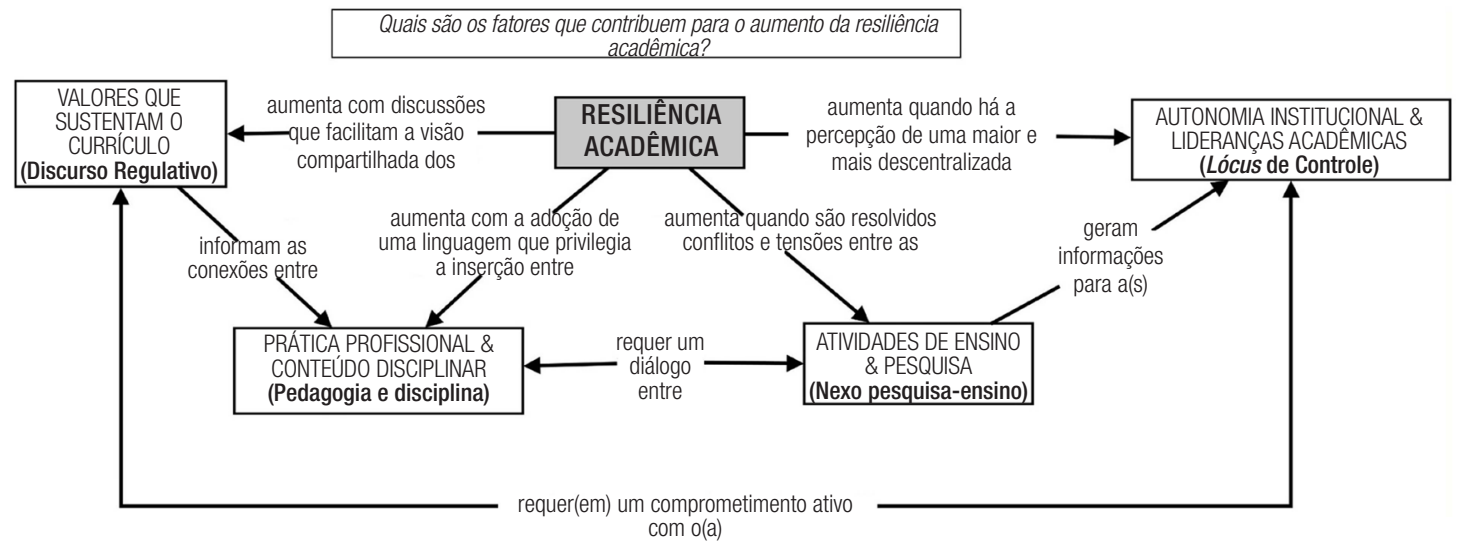

Fonte: os autores.

Por se tratar de um novo panorama teórico (com implicações práticas) para o desenvolvimento pedagógico de docentes universitários, as pesquisas a respeito desse assunto ainda estão em fase de disseminação e merecem ser exploradas, testadas, validadas e adaptadas para nossa realidade educacional. Acreditamos que ainda há espaço na literatura para se discutir a efetividade do modelo nas mais diferentes áreas de conhecimento, bem como o impacto em âmbito individual, departamental e institucional. 


\section{Referências}

AGUIAR, Joana Guilares; CORREIA, Paulo Rogério Miranda. Como fazer bons mapas conceituais? Estabelecendo parâmetros de referências e propondo atividades de treinamento. Revista Brasileira de Pesquisas em Educação em Ciências, Belo Horizonte, v. 13, n. 2, p. 141-157, 2013.

AGUIAR, Joana Guilares; CORREIA, Paulo Rogério Miranda. From representing to modelling knowledge: Proposing a two-step training for excellence in concept mapping. Knowledge Management \& E-Learning, Hong Kong, v. 9, n. 3, p. 366-379, 2017.

ÅKERLIND, Gerlese. Separating the "teaching" from the "academic". Possible unintended consequences. Teaching in Higher Education, Filadélfia, v. 16, n. 2, p. 183-195, 2011.

ALMEIDA, Maria Isabel de; PIMENTA, Selma Garrido. Pedagogia universitária: valorizando o ensino e a docência na universidade de São Paulo. In: PIMENTA, Selma Garrido; ALMEIDA, Maria Isabel de. (Org.). Pedagogia universitária. São Paulo: Edusp, 2009. p. 13-37.

BAILEY, Gillian. Accountability and the rise of "play safe" pedagogical practices. Education + Training, [online], v. 56, n. 7, p. 663-674, 2014. Disponível em: <https://www.emeraldinsight.com/doi/pdfplus/10.1108/ET07-2014-0081>. Acesso em: 22 abr. 2019.

BARNETT, Ronald. A universidade em uma era de supercomplexidade. São Paulo: Anhembi Morumbi, 2005.

BEAUCHAMP, Catherine; THOMAS, Lynn. Understanding teacher identity: an overview of issues in the literature and implications for teacher education. Cambridge Journal of Education, Cambridge, v. 39, n. 2, p. 175-189, 2009.

BERNHEIM, Carlos Tünnermann; CHAUÍ, Marilena de Souza. Desafios da universidade na sociedade do conhecimento: cinco anos depois da conferência mundial sobre educação superior. Brasília, DF: Unesco, 2008.

BERNSTEIN, Basil. Class, codes and control: theoretical studies towards Sociology of Language. London: Routlegde \& Kegan Paul, 1971.

BERNSTEIN, Basil. Pedagogy, symbolic control and identity. Lanham: Rowman \& Littlefield, 2000.

BIGLAN, Anthony. The characteristics of subject matter in different academic areas. Journal of Applied Pychology, Washington, DC, v. 57, n. 3, p. 195-203, 1973.

CAÑAS, Alberto J.; NOVAK, Joseph; REISKA, Pritt. How good is my concept map? Am I a good Cmapper? Knowledge Management \& E-Learning, Hong Kong, v. 7, n. 1, p. 6-19, 2015.

CAÑAS, Alberto J.; REISKA, Pritt; MÖLLITS, Aet. Developing higher-order thinking skills with concept mapping: A case of pedagogic frailty. Knowledge Management \& E-Learning, Hong Kong, v. 9, n. 3, p. 348$365,2017$. 
Joana G. AGUIAR; Paulo Rogério Miranda CORREIA

CLEGG, Andrew; YOUNG. John. The Frailty Syndrome. Clinical Medicine, London, v. 11, n. 1, p. 72-75, 2011.

CLEGG, Sue. Academic identities under threat? British Educational Research Journal, London, v. 34, n. 3, p. 329-345, 2008.

CONTRERAS, José. A autonomia de docentes. São Paulo: Cortez, 2002.

CORREIA, Paulo Rogério Miranda; AGUIAR, Joana Guilares. Profiling pedagogic frailty using concept maps. In: KINCHIN, Ian M.; WINSTONE, Naomi E. (Ed.). Pedagogic frailty and resilience in the university. Roterdã: Sense, 2017. p. 195-210.

CRESWELL, John; POTH, Cheryl. Qualitative inquiry and research design: choosing among five approaches. London: Sage, 2017.

DEMO, Pedro. Educar pela pesquisa. 3. ed. Campinas: Autores Associados, 1998.

DEM0, Pedro. Universidade e qualidade: indagação em torno da qualidade formal e política da formação universitária. Educação Brasileira, Brasília, DF, v. 12, n. 25, p. 61-81, 1990.

DURHAM, Eunice Ribeiro. A autonomia universitária: o princípio constitucional e suas implicações. São Paulo: USP, [1989]. Documento de trabalho 9/89. NUPES e Departamento de Antropologia - FFLCH, São Paulo: Universidade de São Paulo. Disponível em: <http://nupps.usp.br/downloads/docs/dt8909.pdf>. Acesso em: 15 mar. 18.

EGGINS, Heather; MACDONALD, Ranald (Ed.). The scholarship of academic development. País de Gales: Society for Research into Higher Education Open University Press, 2003.

FERNANDEZ, Carmen. Knowledge base for teaching and pedagogical content knowledge (PCK): some useful models and implications for teachers' training. Problems of Education in the 21st Century, Vilnius, v. 60, p. 79-100, 2014.

GOERGEN, Pedro. Ensino superior e formação: elementos para um olhar ampliado de avaliação. Revista da Rede de Avaliação Institucional da Educação Superior, Campinas, v. 4, n. 22, p. 63-76, 2001.

GOERGEN, Pedro. Formação superior: entre o mercado e a cidadania. In: PEREIRA, Elisabete. Universidade e currículo: perspectivas de educação geral. Campinas: Mercado das Letras, 2010. p. 17-40.

GONÇALVES, José Alberto. Desenvolvimento profissional e carreira docente: fases da carreira, currículo e supervisão. Sísifo, Lisboa, n. 8, p. 23-36, 2009.

GROTBERG, Edith Henderson. Introdução: novas tendências em resiliência. In: MELILLO, Aldo; OJEDA, Elbio Néstor Suárez. Resiliência: descobrindo as próprias fortalezas. Porto Alegre: Artmed, 2005. p. 15-22.

HEALEY, Mick. Linking research and teaching to benefit student learning. Journal of Geography in Higher Education, Filadélfia, v. 29, n. 2, p. 183-201, 2005. 
HEIDEMAN, Carroll. Introduction to staff development. In: BURKE, Peter; HEIDEMAN, Robert; HEIDEMAN Carroll (Ed.). Programming for staff development. London: Falmer Press, 1990. p. 3-9.

HOSEIN, Anesa. Pedagogic frailty and research-teaching nexus. In: KINCHIN, lan; WINSTONE, Naomi (Ed.). Pedagogic frailty and resilience in the university. Roterdã: Sense, 2017. p. 135-150.

HOWARD, Sue; JOHNSON, Bruce. Resilient teachers: resisting stress and burnout. Social Psychology of Education, New York, v. 7, n. 4, p. 399-420, 2004.

ISAIA, Silvia Maria de Aguiar; BOLZAN, Doris Pires Vargas. Pedagogia universitária e desenvolvimento profissional docente. Porto Alegre: Edipucrs, 2009.

KINCHIN, lan (Ed.). Novakian concept mapping in university and professional education. Knowledge Management \& E-Learning, Hong Kong, v. 7, n. 2, p. 1-178, 2015 a.

KINCHIN, lan. Pedagogic frailty: an initial consideration of aetiology and prognosis. In: ANNUAL CONFERENCE OF THE SOCIETY FOR RESEARCH INTO HIGHER EDUCATION (SRHE), 2015, País de Gales. Proceedings... País de Gales: [s. n.], 2015b. Disponível em: <https://www.srhe.ac.uk/conference2015/abstracts/0026. pdf>. Acesso em: 15 mar. 2018.

KINCHIN, lan. The mapping of pedagogic frailty: a concept in which connectedness is everything. In: CAÑAS, Alberto; REISKA, Pritt; NOVAK, Joseph (Eds.). Innovating with concept maps (pp. 229-240). Suiça: Springer, 2016a.

KINCHIN, lan. Visualising powerful knowledge to develop the expert student: a knowledge structures perspective on teaching and learning at university. Roterdã: Sense, 2016b.

KINCHIN, lan. Visualising the pedagogic frailty model as a frame for the scholarship of teaching and learning, PSU Research Review, Arábia Saudita, v. 1, n. 3, p. 184-193, 2017.

KINCHIN, lan; CABOT, Lyndon. Framed autoethnography as an approach for uncovering pedagogic frailty. Contemporary Educational Researches Journal, Chipre, v. 6, n. 1, p. 40-47, 2016.

KINCHIN, lan; FRANCIS, Robert. Mapping pedagogic frailty in geography education: a framed autoethnographic case study. Journal of Geography in Higher Education, Filadélfia, v. 41, n. 1, p. 56-74, 2017.

KINCHIN, Ian; HAY, David. The myth of the research-led teacher. Teachers and Teaching, Filadélfia, v. 13, n. 1, p. 43-61, 2007.

KINCHIN, Ian; LYGO-BAKER, Simon; HAY, David. Universities as centre of non-learning. Studies in Higher Education, Filadélfia, v. 33, n. 1, p. 89-103, 2008.

KINCHIN, Ian; STREATFIELD, David; HAY, David. Using concept mapping to enhance the research interview. International Journal of Qualitative Methods, London, v. 9, n. 1, p. 52-68, 2010. 
KINCHIN, Ian; WINSTONE, Naomi (Ed.). Pedagogic frailty and resilience in the university. Roterdã: Sense, 2017.

KINCHIN, lan et al. Charting the elements of pedagogic frailty. Educational Research, Filadélfia, v. 58, n. 1, p. 1-23, 2016.

KREBER, Carolin. Academics' teacher identities, authenticity and pedagogy. Studies in Higher Education, Filadélfia, v. 35, n. 2, p. 171-194, 2010.

LIGHT, Greg; CALKINS, Susanna. The experience of academic learning: uneven conceptions of learning across research and teaching. Higher Education, New York, v. 69, n. 3, p. 345-359, 2015.

MAGALHÃES, Solange Martins Oliveira. Trabalho, pesquisa e ensino: tensões e desafios para a docência no ensino superior. Psicologia, São Paulo, v. 4, n. 1, p. 60-78, 2013.

NOVA, Carla Carolina Costa da; SOARES, Sandra Regina. A relação entre ensino e pesquisa na formação inicial de docentes, na visão de docentes universitários. Revista Educação e Emancipação, Brasília, DF, v. 5, n. 2, p. 83-105, 2012.

NOVAK, Joseph. Learning, creating, and using knowledge: concept maps as facilitative tools in schools and corporations. New York: Routledge, 2010.

PUHL, Mário José; DRESCH, Óbserson Isac. 0 princípio da indissociabilidade entre ensino, pesquisa e extensão e o conhecimento. Dialogus, Cruz Alta, v. 5, n. 1, p. 37-55, 2016.

ROBERTSON, Jane. Beyond the "research/teaching nexus": exploring the complexity of academic experience. Studies in Higher Education, Filadélfia, v. 32, n. 5, p. 541-556, 2007.

ROBERTSON, Jane; BOND, Carol. Experiences of the relation between teaching and research: what do academics values? Higher Education Research \& Development, Filadélfia, v. 20, n. 1, p. 5-19, 2001.

ROCKWOOD Kenneth. Frailty and its definition: a worthy challenge. Journal of American Geriatric Society, Hoboken, v. 53, n. 6, p. 1069-1070, 2005.

SANTOS, Lucíola Licínio. Bernstein e o campo educacional: relevância, influências e incompreensões. Cadernos de Pesquisa, São Paulo, n. 120, p. 15-49, 2003.

SCHÖN, Donald. Educando o profissional reflexivo: um novo design para 0 ensino e a aprendizagem. Tradução de Roberto Cataldo Costa. Porto Alegre: Artmed, 2000.

SHAFFER, David Williamson; RESNICK, Mitchel. "Thick" authenticity: new media and authentic learning. Journal of Interactive Learning Research, Waynesville, v. 10, n. 1, p. 195-215, 1999.

SOUSA, Antonio Paulino. Entre a pesquisa e o ensino na Universidade. Revista Perspectivas Sociais, Pelotas, v. 3, n. 1, p. 1-27, 2014. 
SOUSA SANTOS, Boaventura. A universidade no século XXI: para uma reforma democrática e emancipatória da universidade. São Paulo: Cortez, 2010.

STEVENSON, Jacqueline; BURKE, Penny-Jane; WHELAN, Pauline. Pedagogic stratification and the shifting landscape of higher education. New York: The Higher Education Academy, 2014. Disponível em: <https:// www.heacademy.ac.uk/system/files/hub/download/pedstrat_finalreport.pdf>. Acesso em: 15 mar. 2018.

STOECKER, Judith. The Biglan classification revisited. Research in Higher Education, New York, v. 34, n. 4, p. $451-463,1993$.

TALBOT, Martin. Monkey see, monkey do: A critique of the competency model in graduate medical education. Medical Education, Hoboken, v. 38, n. 6, p. 587-592, 2004.

TAVARES, José (Org.). Resiliência e educação. São Paulo: Cortez, 2001.

TORRES, Alda Roberta. A pedagogia universitária e suas relações com as políticas institucionais para a formação de docentes do ensino superior. 2014. Tese (Doutorado em Educação) - Faculdade de Educação, Universidade de São Paulo, São Paulo, 2014.

UNESCO. Towards knowledge societies: Unesco world report. Paris: Unesco, 2005.

VERAS, Renato Peixoto et al. Promovendo a saúde e prevenindo a dependência: identificando indicadores de fragilidade em idosos independentes. Revista Brasileira de Geriatria e Gerontologia, Rio de Janeiro, v. 10, n. 3, p. 355-370, 2007.

VIEIRA, Flavia; SILVA, José Luis; ALMEIDA, Judite. Transformar a pedagogia na universidade: possibilidades e constrangimentos. In: VIEIRA, Flavia (Org.). Transformar a pedagogia na universidade: narrativas da prática. Lisboa: De Facto, 2009. p. 17-38.

WILEY, Christopher; FRANKLIN, Jo. Framed autoethnography and pedagogic frailty: a comparative analysis of mediated concept maps. In: KINCHIN, lan; WINSTONE, Naomi. (Ed.). Pedagogic frailty and resilience in the university. Roterdã: Sense, 2017. p. 17-32.

WINSTONE, Naomi. The '3Rs' of pedagogic frailty: risk, reward and resilience. In: KINCHIN, lan; WINSTONE, Naomi (Ed.). Pedagogic frailty and resilience in the university. Roterdã: Sense, 2017. p. 33-48.

YOUNG, Michael. Teoria do currículo: 0 que é e por que é importante. Tradução de Leda Beck. Cadernos de Pesquisa, São Paulo, v. 44, n. 151, p. 190-202, 2014.

YOUNG, Pat. Out of balance: lectures' perceptions of differential status and rewards in relation to teaching and research. Teaching in Higher Education, Filadélfia, v. 11, n. 2, p. 191-202, 2006.

Recebido em: 22.03.2018

Revisões em: 21.08 .2018 Aprovado em: 17.10.2018 
Joana Aguiar é mestre e doutora em Ensino de Ciências pela USP, tendo pesquisado o uso dos mapas conceituais no processo de ensino e aprendizagem de química. Atualmente, pesquisa acerca da resiliência acadêmica e o desenvolvimento pedagógico de docentes do Ensino Superior.

Paulo Correia é professor da Escola de Artes, Ciências e Humanidades da USP e coordenador do Grupo de Pesquisa Mapas Conceituais. Suas investigações incluem o uso dos mapas conceituais no processo de ensino e aprendizagem, incluindo sala de aula e ambiente virtual de aprendizagem. 